\title{
ESTUDO DA ESTABILIDADE OPERACIONAL EM RECICLO CONTÍNUO DIRETO DA LIPASE B DE Candida antarctica IMOBILIZADA EM ESPUMA FLEXÍVEL DE PU DE DENSIDADE 30 E18
}

\author{
ANTUNES, A. ${ }^{1}$, FICANHA, A. M. M. ${ }^{1}$, NYARI, N.L.D. ${ }^{1}$, ZAMADEI, R. ${ }^{1}$, M. BOPSIN ${ }^{1}$, K. L. \\ LEVANDOSKI $^{1}$, A. R. PAULAZZI ${ }^{1}$, ZENI, J. ${ }^{1}$, DALLAGO, R.M. ${ }^{1}$ \\ ${ }^{1}$ Universidade Regional Integrada do Alto Uruguai e das Missões - Campus de Erechim, \\ Departamento de Engenharia de Alimentos, Erechim, Rio Grande do Sul, Brasil \\ nenaantunes@gmail.com
}

\begin{abstract}
RESUMO - Os processos que utilizam lipases são especialmente atraentes em função das diferentes aplicações. A enzimas imobilizadas possibilita uma maior estabilidade e a produção de biocatalisadores com aplicações industriais. O poliuretano permite o reuso da enzima reduzindo os custos de produção além de facilidade no processo. O presente trabalho teve como objetivo a imobilização da lipase Candida antarctica B (Novozyme) em espuma flexível de PU de densidades diferente (D18 e D30), avaliando a capacidade de reuso na síntese do etiloleato. Para a avaliação do processo de reutilização, após cada reação da quantificação da atividade de esterificação, o excedente do produto da reação de esterificação era retirado. Em seguida uma nova quantidade de solução padrão $5 \mathrm{~mL}$ (ácido oleico:etanol) era adicionado ao imobilizado e era realizado uma nova reação e assim sucessivamente até o imobilizado atingir $50 \%$ da sua atividade residual inicial. A quantificação da atividade de esterificação foi realizada por titulometria. Ao final do estudo foi observado um total de 6 e 4 reciclos com atividade residual de $50 \%$ para os imobilizados em espuma flexível de PU- D18 e D30 respectivamente. Para a enzima livre o número de reciclos foram 4 , porem, com atividade enzimática menor que $20 \%$.
\end{abstract}

\section{INTRODUÇÃO}

As lipases têm sido utilizadas com grande sucesso com para catalisar reações de esterificação, transesterificação e interesterificação, pois representam melhorias significativas no processo, principalmente no que se refere aos custos operacionais, como no tempo de reação, consumo de energia, mão de obra e alta atividade catalítica (Pires-Cabral et al., 2010). Sendo utilizados tanto na indústria (alimentos, cosméticos e perfumes, biomédicos, pesticidas, detergentes) e em níveis acadêmicos (Brígida et al., 2010; Nyari, 2013).

Ésteres etílicos (oleatos) também podem ser utilizados como plastificantes e lubrificantes, aditivos biológicos e fluidos hidráulicos, sendo assim uso têm sido dificultados devido aos baixos valores e a incapacidade de reutilização, alem de técnicas para a conservação de alimentos através da adição de ésteres etílicos. No entanto, a maior parte destes produtos é obtida por via química. Sendo assim, sugere a incorporação de novas técnicas para a produção de compostos biodegradáveis, biocompatíveis e essencialmente não- 
tóxicos. Em resumo, a produção biotecnológica destes produtos na indústria de alimentos esses compostos têm várias vantagens sobre os ésteres sintéticos, tais como degradabilidade; podem ser sintetizadas a partir de substratos renováveis, condições reacionais brandas envolvidos, elevado grau de pureza alcançado e a baixa toxicidade (Neta et al., 2012).

O objetivo do presente estudo foi desenvolver através do método de esterificação do ácido oleico com etanol a produção de ésteres de oleato de etila utilizando uma lipase do tipo $\mathrm{B}$ de Candida antarctica imobilizada em situ em espuma flexível de poliuretano (PU), sendo conhecida pela capacidade e versatilidade de imobililizar enzimas, enfatizando a atividade do catalizador e estabilidade operacional em reaçoes de estereficação.

\section{MATERIAIS E MÉTODOS}

A enzima utilizada foi a lipase de Candida antarctica B (Novozyme NZL-102-LYOHQ) e a proporção dos monômeros, surfactantes, extensores de cadeia e água para as diferentes densidade de estudos, foram cedidas pela empresa Tasca Estofados e Cia (empresa produtora de espuma flexível de poliuretano). Os solventes utilizados foram hexano (Quimex 97\% de pureza), metanol (Quimex 97\% de pureza) e etanol (Quimex 97\% de pureza).

\subsection{Imobilização}

O procedimento experimental para imobilização da Candida antarctica B (CAL B) em espuma flexível de PU de densidade 30 e 18, foi realizada utilizando a proporção dos monômeros, surfactantes, extensores de cadeia e água, proporções essa cedidas pela empresa Tasca Estofados e Cia (empresa produtora de espuma flexível de poliuretano), a qual também ofertou as matérias primas para a fabricação da espuma flexível de PU.

O emprego da enzima foi em estado líquido, com preparo de solução enzimática ( $2 \mathrm{~g}$ em $20 \mathrm{~mL}$ de água destilada). O imobilizado foi produzido pela mistura da enzima em solução (correspondendo a $10 \%$ do volume total dos monômeros). O processo de preparo para imobilização da Candida antarctica B em espuma flexível de PU de densidade 30, inicia com a mistura dos monômeros (poliol e copolímero) em um béquer, os quais são homogeneizados por 15 segundos. Em seguida é adicionada a essa mistura a solução enzimática a qual também se faz a homogeneização. Após é incorporado a mistura do béquer, a ASA (amina, silicone e água), em concomitante é feita a adição do estanho, e por fim é vertido ao béquer o isocianato o qual dá o "star" da polimerização. A mistura completa é polimerizada em forma de alumínio previamente untada com vaselina sólida. Para ambas as densidades o procedimento de imobilização foi o mesmo.

Após aproximadamente 1 minuto ocorreu a expansão da espuma e completa polimerização da mesma, possibilitando visualizar algumas características da espuma formada, como conformação, flexibilidade, maciez, firmeza, porosidade interna e resistência (Zaiat 1996, Lucas et al. 2001; Santos 2011). Cabe ressaltar que o método de imobilização utilizado nesta pesquisa consiste no método de encapsulamento, onde ocorre a formação de uma estrutura porosa na presença da enzima, envolvendo-a em uma estrutura tridimensional, realizando o "confinamento" da proteína no polímero insolúvel, resultando no biocatalisador imobilizado (Dalla-Vecchia et al., 2004; Gonçalves, 2007). 


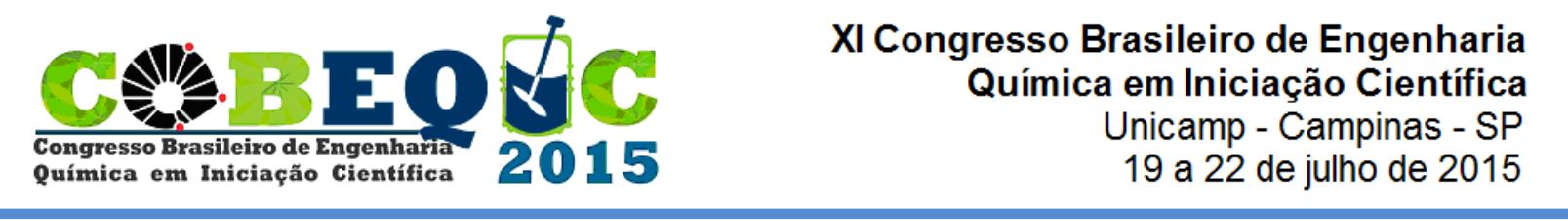

\subsection{Atividade Enzimática- Esterificação}

A atividade de esterificação das foi realizada pela quantificação da reação de síntese do ácido oleico e etanol (razão molar 1:1 (v/v)). A reação foi conduzida a $40{ }^{\circ} \mathrm{C}, 160 \mathrm{rpm}$ por 40 min. Esta foi iniciada pela adição da enzima $(0,1 \mathrm{~g})$ ao meio reacional, em frascos de vidro com tampa, mantidos em agitador orbital. Alíquotas de $500 \mu \mathrm{L}$ foram retiradas do meio reacional em triplicata no início da reação. A cada amostra foram adicionados $15 \mathrm{~mL}$ de uma solução de acetona-etanol (1:1) (v/v) para paralisar a reação e para extração de éster de oleato de etila segundo Paroul et al., (2010 e 2011). A quantidade de ácido consumida foi determinada por titulação com $\mathrm{NaOH} 0,05 \mathrm{M}$ até $\mathrm{pH}$ 11. Uma unidade de atividade enzimática foi definida como a quantidade de enzima que consome $1 \mu \mathrm{mol}$ de ácido graxo por minuto, nas condições do ensaio. A atividade enzimática foi calculada baseando em Brígida et al., 2010).

\subsection{Determinação do Rendimento}

O rendimento do imobilizado foi calculado pela porcentagem da razão da atividade total da enzima livre em solução utilizado na imobilização e da atividade total do imobilizado (o qual considera a massa total de imobilizado produzido (Brígida et al., 2010).

\section{RESULTADO E DISCUSSÕES}

A reutilização de enzimas em mais de um ciclo de reação é um dos principais objetivos da imobilização, este fato é importante para as enzimas devido ao seu preço elevado, visto que, o custo da enzima é um dos principais problemas quando se refere a sua aplicação industrial. Normalmente, considera-se que uma enzima pode ser reutilizada até a sua atividade ser maior ou igual a $50 \%$ do valor da atividade inicial (Ficanha, 2014).

A possibilidade de reutilizar a lipase de Candida antarctica B imobilizada foi determinada por reações de síntese de oleato de etila empregando dois diferentes métodos de reusos: Reuso contínuo (sem lavagem) e a cada 24 horas com lavagem em diferentes solventes orgânicos, apresentados nas Figuras 1. 


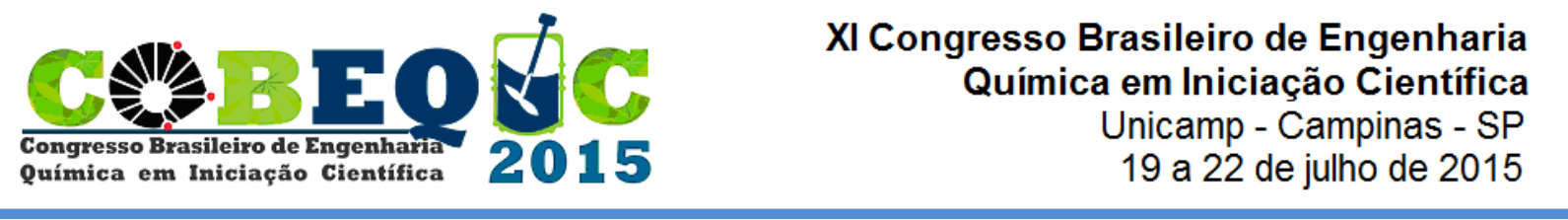

Figura 1 - Número de reciclos da lipase imobilizada em PU de densidade D30, D18 e da lipase Novozyme 435 com reuso contínuo.

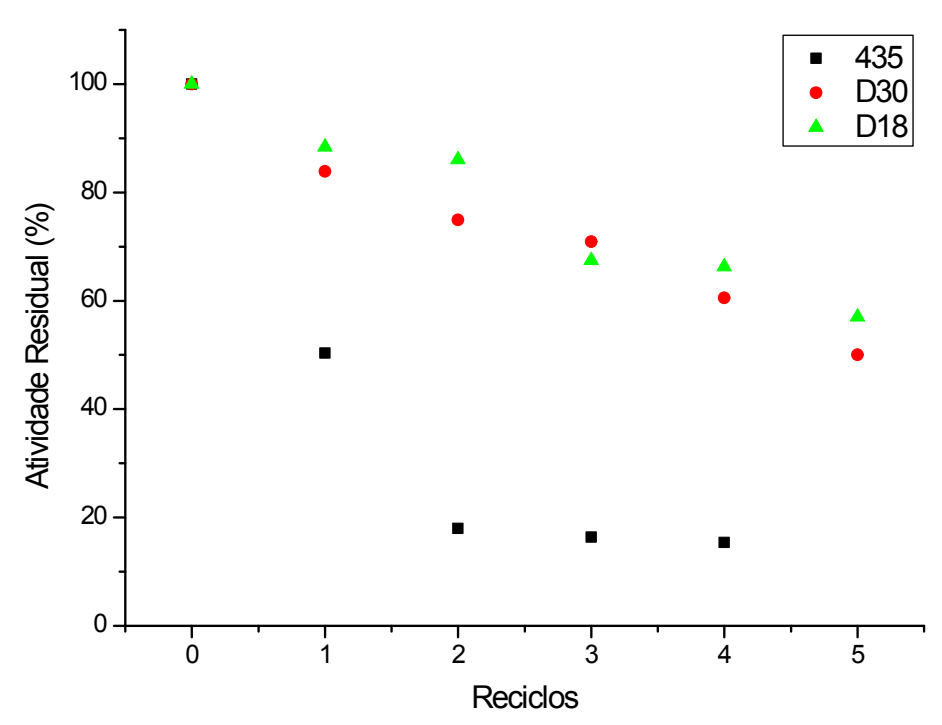

Como pode-se observar na Figura 1, a lipase imobilizada em poliuretano de densidade D30 e D18, apresentou um numero de reciclos igual a 5, com atividade residual em torno de $50 \%$ no 5 reciclo, ou seja, estas enzimas imobilizadas (D30 e D18) poderiam ser utilizadas em torno de 5 vezes em um mesmo processo reacional para síntese do oleato de etila. Já a lipase Novozyme 435, no processo reacional para síntese do oleato de etila, perdeu $50 \%$ de sua atividade residual no 1 ciclo, e a partir do 2 ciclo apresentou atividade residual em torno de $20 \%$.

Ao se comparar a enzima lipase Novozyme 435 com a lipase imobilizada no suporte de poliuretano de diferentes densidades, D30 e D18, pode-se verificar que a enzima imobiliza no poliuretano, independentemente de sua densidade, apresenta um numero maior de reciclos e com atividade residual superior a 50\%. Nyari, (2013), estudando o processo de imobilização de CALB em PU rígido obteve 30 reciclos em sistema de reuso contínuo, resultado este, supeior aos obtidos no presente estudo com PU flexível.

\section{CONCLUSÕES}

Os resultados do reciclo contínuo demostraram a possibilidade de reutilizar a enzima imobilizada D30 e D18 por até 5 vezes, considerando 50\% de atividade residual, em contra partida observou- se que a enzima comercial Novozyme 435 apresentou apenas 1 ciclo no mesmo processo.

\section{REFERÊNCIAS BIBLIOGRÁFICAS}

BRÍGIDA, A. I. S.; CALADO, V. M. A.; GONÇALVES, L. R. B.; COELHO, M. A. Z. Effect of chemical treatments on properties of green coconut fiber. Carbohydr. Polym, v. 79, p. 832-838, 2010. 
DALLA VECCHIA, C.; BOWER, R. G.; THEUNS, T.; BALOGH, M. L.; MAZZOTTA, P., FRENK, C. S. Quenching cluster cooling flows with recurrent hot plasma bubbles. Mon Not R Astron Soc, v. 355, p. 995-1004, 2004.

FICANHA, M. M. A. Imobilização de Lipase de Candida antarctica B (CalB) pela técnica de sol-gel. Dissertação (Mestrado em Engenharia Alimentos) Universidade Regional Ingrada do Alto Uruguai e das Missões - Campus de Erechim, URI, 2014.

GONÇALVES, F. A. G. Produção de lipase extracelular por leveduras em cultivo submerso. Belo Horizonte, Dissertação de Mestrado. Departamento de Ciências de Alimentos da Universidade Federal de Minas Gerais. 2007

NETA, N. S.; CUNHA, J. A. C.; SANCHO, S. O.; ABREU, R. F. A.; PONTES, D. F.; CARIOCA, J. O. B.; TEIXEIRA, J. A. (2012). Enzymatic Production of Ethyl Oleate Ester Using a Lipase from Candida antarctica B. Holos-Issn v. 2, p. 1807-1600, 2012.

NYARI, N. L. D. Estudo da Imobilização de Lipase de Candida antarctica B em Poliuretano. Dissertação de Mestrado em Engenharia de Alimentos da Universidade Regional Integrada do Alto Uruguai e das Missões - URI, Erechim, 2013

PAROUL, N.; BIASI, A.; ROVANI, A. C.; PRIGOL, C.; DALlAGO, R.; TREICHEL, H.; OLIVEIRA, D. Enzymatic production of linalool esters in organic and solvent-free system. Bioprocess Biosyst Eng, v. 33, p. 583-589, 2010.

PAROUL, N.; GRZEGOZESKI, L. P.; CHIARADIA, V.; TREICHEL, H.; CANSIAN, R. L.; OLIVEIRA, J. V.; OLIVEIRA, D. Solvent-free geranyloleate production by enzymatic esterificarion. Bioprocess Biosyst Eng, v. 34, p. 323-329, 2011.

PIRES-CABRAL, P.; FONSECA, M. M. R.; FERREIRA-DIAS, S. Modelling the production of ethyl butyrate catalysed by Candida rugosa lipase immobilized in polyurethane foams. Chem. Biochem. Eng, v. 33, p. 148-158, 2007.

SANTOS, R. D. Produção Enzimática de Poli (E-Caprolactona) em Dióxido de Carbono Supercrítico. Universidade Federal de Santa Catarina, Centro Tecnológico, Programa de Pós-Graduação em Engenharia de Alimentos, Florianópolis/SC, 2011. 